\title{
POSIÇÃO DO CRESCIMENTO DO PIB DE ANGOLA NA SADC ANTES E APÓS A CRISE DE 2008 E EFEITOS NA ECONOMIA DA REGIÃO E DO PAÍS
}

\author{
Heitor Simão Afonso Ambrósio ${ }^{1}$
}

\begin{abstract}
RESUMO: O objetivo deste artigo é mostrar de forma comparativa o comportamento da taxa de crescimento do PIB real de Angola em relação aos demais países da SADC e seu posicionamento na região. Também, pretende-se saber se este comportamento tem tido efeitos positivos sobre o desenvolvimento da economia da região e do país. Desde 2004, Angola tem mostrado níveis elevados de taxas de crescimento do PIB influenciado pela estabilidade política, do aumento da produção e exportação do petróleo. Porém, este fato tem-se traduzido na porta de entrada aos investidores estrangeiros, além de aumentar o seu posicionamento na SADC. Além do mais, o governo tem aumentado os investimentos em infraestruturas de apoio ao desenvolvimento econômico e diversificado a economia para evitar no futuro, choques adversos a produção e exportação do petróleo evitando ciclos econômicos e, garantindo desta forma a forte posição na região. Ademais, este efeito crescimento do PIB tem criado outros efeitos estruturais e conjunturais de forma positiva como o aumento do nível de emprego, de renda, diminuição da extrema pobreza, da inflação e, o fortalecimento das instituições do estado através do espírito democrático entre outros (MINPLAN: PLANO NACIONAL DE DESENVOLVIMENTO, 2013 2017). ${ }^{2}$
\end{abstract}

PALAVRAS-CHAVES: PIB; Posição na SADC; Economia; Sociedade; Angola.

Recebido em Julho, 2013: Aceito em Novembro, 2013:

Para citar este artigo:

AMBRÓSIO, Heitor. "Posição do crescimento do PIB de Angola na SADC antes e após a crise de 2008 e efeitos na economia da região e do país" In: Revista Intratextos, 2013, vol 5, no1, p. 42-63. DOI: http://dx.doi.org/10.12957/intratextos.2013.10575

\footnotetext{
${ }^{1}$ Mestre em Economia pela Universidade Federal de Uberlândia. Bolsista do INAGBE-Angola. Email: heitorocker@gmail.com

2 Por limitação de fontes bibliográficas sobre o tema, parte da explanação do artigo foi escrito em decorrência da minha vivencia e das investigações feitas em Angola para a dissertação de mestrado. As siglas PIB e SADC relacionadas ao resumo têm os seus significados na forma: PIB - produto interno bruto. SADC - Comunidade de Desenvolvimento da África Austral.
} 


\section{Introdução}

Após o termino da guerra civil em 2002, que começara em meados dos anos 70, Angola é um país que no "ar da sua graça", veio dando mostras de elevadas taxas de crescimento econômico na África e no mundo influenciado pelo aumento da produção e dos altos níveis do preço do petróleo. Através dos dados fornecidos pelo Banco Mundial (2013) e pelo Fundo Monetário Internacional (2011), Angola atinge o boom econômico se assim considerarmos entre os anos de 2006 á 2007 conforme os dados da tabela 3 de Matos (2011), apesar de se verificar no ano seguinte um abrandamento.

Atento ao abrandamento da economia, a luta do governo foi e é atualmente manter níveis consideráveis de taxas de crescimento para fortalecer o seu posicionamento na região. Ademais, a diversificação da economia é um passo a se enfrentar com vistas a manter nos próximos anos um ambiente saudável da economia atendendo a vulnerabilidade a choques externos.

Contudo, outra formula é a reorganização da contabilidade nacional que já é um processo que tem estado a criar efeitos e progressos no quesito de políticas macroeconômicas conforme afirma também o Fundo Monetário Internacional (FMI) no seu relatório de n. ${ }^{\circ}$ 14/81 sobre a segunda monitorização pós- programa. Porém, atento a este fato, o Fundo Monetário Internacional (FMI) através do acordo stand-by ${ }^{3}$ (CMI/CEIC ${ }^{4}, 2010$, p.46 apud FMI, 2009) tem acompanhado passo a passo o desenrolar deste crescimento, e auxiliado o governo no processo de reorganização das contas públicas com o objetivo segundo o economista angolano e diretor do Jornal Expansão

3 O Stand by Arregemente ou SBA (acordo stand by) é o mecanismo de assistência financeira mais utilização do FMI, geralmente prestado aos países de renda média, entre os quais se situa Angola. $\mathrm{O}$ referido programa serve para auxiliar países com problemas de pagamentos no exterior a honrar os seus compromissos financeiros de curto prazo, equilibrando assim a balança de pagamentos e estabilizando a sua primeira avaliação respectiva moeda. Disponível em: http://www.opais.net/pt/opais/?det=10500.

4 Instituto Chr Michelsen: é um centro independente de pesquisa em desenvolvimento internacional e políticas públicas com foco em países pobres. O Instituto conduz pesquisa básica e aplicada, nas áreas temáticas de direitos humanos, redução de pobreza, reforma do setor público, resolução de conflitos e manutenção de paz. Enfoque geográfico é dado a África do Norte e subsaariana, Oriente Médio, Ásia Central e Sudeste Asiático, e América Latina. A pesquisa realizada pelo CMI tem como objetivo informar e influenciar políticas públicas assim como contribuir para o debate sobre desenvolvimento internacional. $\mathrm{O}$ CMI trabalha com uma vasta rede de pesquisadores parceiros e em estreita cooperação com pesquisadores no Sul. CEIC: Centro de Estudos e Investigação Cientifica da Universidade Católica de Angola. 
Carlos Rosa, "de estabilização macroeconômica, a recomposição das reservas que haviam baixado muito devido à crise financeira internacional de 2008, e a estabilização da moeda nacional", 5 instrumentalizadas num relatório.

O controle das contas do governo tem evidenciando políticas fiscais controláveis e seguras através do seu instrumento tradicional, o OGE (orçamento geral do estado) facilitando assim, políticas de redistribuição e alocação da riqueza de formas a influenciar o desenvolvimento socioeconômico do interesse de uma sociedade em processo de democratização. Embora se tenha um longo caminho a percorrer, as evidencias atuais do plano de governo sobre a alocação dos recursos já se mostram satisfatórias principalmente no campo social com foco ao desenvolvimento rural para redução da pobreza (AÇÃO PARA O DESENVOLVIMENTO RURAL E AMBIENTE. PLANO ESTRATÉGICO 2012-2016). Outros exemplos de âmbito social claros são: as novas estruturas habitacionais, escolares, de saúde que vem se formando todos os dias, as vias transnacionais que ligam as capitais de províncias para melhorar a mobilidade social, etc. (GOVERNO DE ANGOLA, 2010 at MINPLAN, 2012).

Não podemos esquecer que, a estabilidade política ( $p a z$ efetiva), revitalização das infraestruturas, níveis elevados de produção do petróleo e a diversificação econômica como fenômenos de mudança social são condições sine qua non para manter a economia de Angola estável e em condições favoráveis de posicionamento entre as economias que mais cresceram e crescem na região da SADC.

Por conseguinte, o estudo comporta três pontos além da introdução, no qual os dois primeiros ser-lhe-ei muito breve: o primeiro versará na demonstração de alguns conceitos teóricos relevantes ao enquadramento do estudo como espaço/região e crescimento econômico. O segundo será a delimitação de Angola na SADC através da ilustração de um mapa para tornar mais visível e pragmático a análise de sua localização espacial, ou seja, a proximidade entre os países. Em seguida, abordarei através de dados metodológicos fatos que irão tornar o estudo mais relevante por via de alguns indicadores

5 Carlos Rosado. Artigo: Acordo Stand-by é a melhor coisa que aconteceu ao país. 22-01-2013 | Fonte: Angop. Disponível em: <http://www.angonoticias.com/Artigos/item/37294/acordo-stand-by-e-a-melhorcoisa-que-aconteceu-ao-pais>. 
econômicos colhidos de instituições como as Instituições de Bretton Woods, Ministério das Finanças, do Planejamento, do Banco Nacional de Angola entre outras de forma a espelhar concretamente o que se vem lavrando (crescimento e posicionamento), se necessário, por meio de quadros, gráficos ou mesmo tabelas para tornar mais analítico, fiável e consistente o estudo.

\section{Conceito de Espaço, Região e Crescimento Econômico.}

2.1 A idéia de espaço

A idéia de se conceituar o termo espaço vem da necessidade de distingui-lo do conceito de região. A idéia de Espaço se diferencia da noção de região pela restrição de contiguidade. A região, necessariamente, precisa ser constituída por um território contínuo, delimitado por uma fronteira. $\mathrm{O}$ espaço econômico pode ter descontinuidades. Para Milton Santos (1997), o espaço é entendido como "um conjunto de sistemas de objetos e de sistemas de ações". No espaço, segundo o mesmo autor, se reúnem materialidade e ação humana.

\subsection{A idéia de Região}

Uma Região forma uma identidade, apresentando características semelhantes. Ela apresenta como um campo de forças, atraindo unidades econômicas e organizando todo o território à sua proximidade. Definida provisoriamente como um subespaço do território nacional, a região se relaciona com outras regiões, incluindo o exterior do país em que está inserida.

Milton Santos (1993) em sua obra A Ubarnização Brasileira, "expõe que a Região deixa de ser um produto da solidariedade orgânica localmente tecida, para tornarse resultante da solidariedade organizacional". Quanto aos critérios de delimitação do espaço regional na pesquisa histórica.

Silva (1990) entende que a região só pode ser vista no âmbito do enfoque sistêmico. Desta forma, a região se constitui em um subsistema de um todo com o qual mantêm inter-relações. Para esta autora, as fronteiras regionais podem ou não coincidir 
com as divisões juridicamente estabelecidas, pois se ampliam ou diminuem, no decorrer do tempo, em função de ajustes de natureza política. Portanto, segundo esta autora, para se delimitar uma região, não se deve levar em conta apenas os aspectos jurídicoadministrativos, nem somente aspectos exclusivamente econômicos, mas os de ordem social e, sobretudo político.

\subsection{Conceito de Crescimento Econômico}

Não podemos deixar de compreender o conceito de crescimento econômico sem distingui-lo do conceito de desenvolvimento econômico visto que muita das vezes tem criado conflito aos leitores. Portanto, o crescimento econômico pode ser definido como sendo o aumento sustentado de uma unidade econômica durante um ou vários períodos longos. A sua avaliação faz-se através da analise de indicadores tradicionais como o Produto Interno Bruto (PIB) ou Produto Nacional Bruto (PNB), como também em outras situações através do "PIB per capita ou Rendimento médio por habitante" segundo Sobral (2011). Porém, "o desenvolvimento econômico, consiste em um processo de acumulação de capital e incorporação de progresso técnico ao trabalho e ao capital ocasionando o aumento da produtividade, dos salários, e do padrão médio de vida da população". (BRESSER-PEREIRA, 2008, p.1). Segundo o autor,

O desenvolvimento econômico visa atender de forma direta, um objetivo político fundamental das sociedades modernas, o bem estar, e indiretamente busca segurança, liberdade, justiça social e proteção do meio ambiente, dessa forma o desenvolvimento econômico implicam mudanças estruturais, culturais e institucionais (BRESSER-PEREIRA, 2008, p.2).

Entretanto, o termo crescimento econômico distingue-se de desenvolvimento econômico por significar um aumento quantitativo da produção, mas sem a preocupação com melhoria das condições de vida da sociedade, dessa forma, o desenvolvimento econômico é a busca da qualidade de bem-estar de forma conjugada de uma determinada sociedade através de política de alocação de recursos financeiros.

\section{A Delimitação de Angola na África Austral (SADC)}


A República de Angola é um país africano, localizado na região da África Austral, limitado ao Norte pela República Democrática do Congo e República do Congo, ao Sul pela República da Namíbia, a Leste pela República Democrática do Congo e pela República da Zâmbia e a Oeste pelo oceano atlântico. A sua extensão é de 1.246 .700 km², sendo que, o número da população em 2010 rondou em 18 milhões. ${ }^{6}$ Ainda se configura o enclave de Cabinda que faz parte da Republica de Angola, mas separado pelo mesmo oceano.

Figura 1 - Delimitação de Angola na SADC

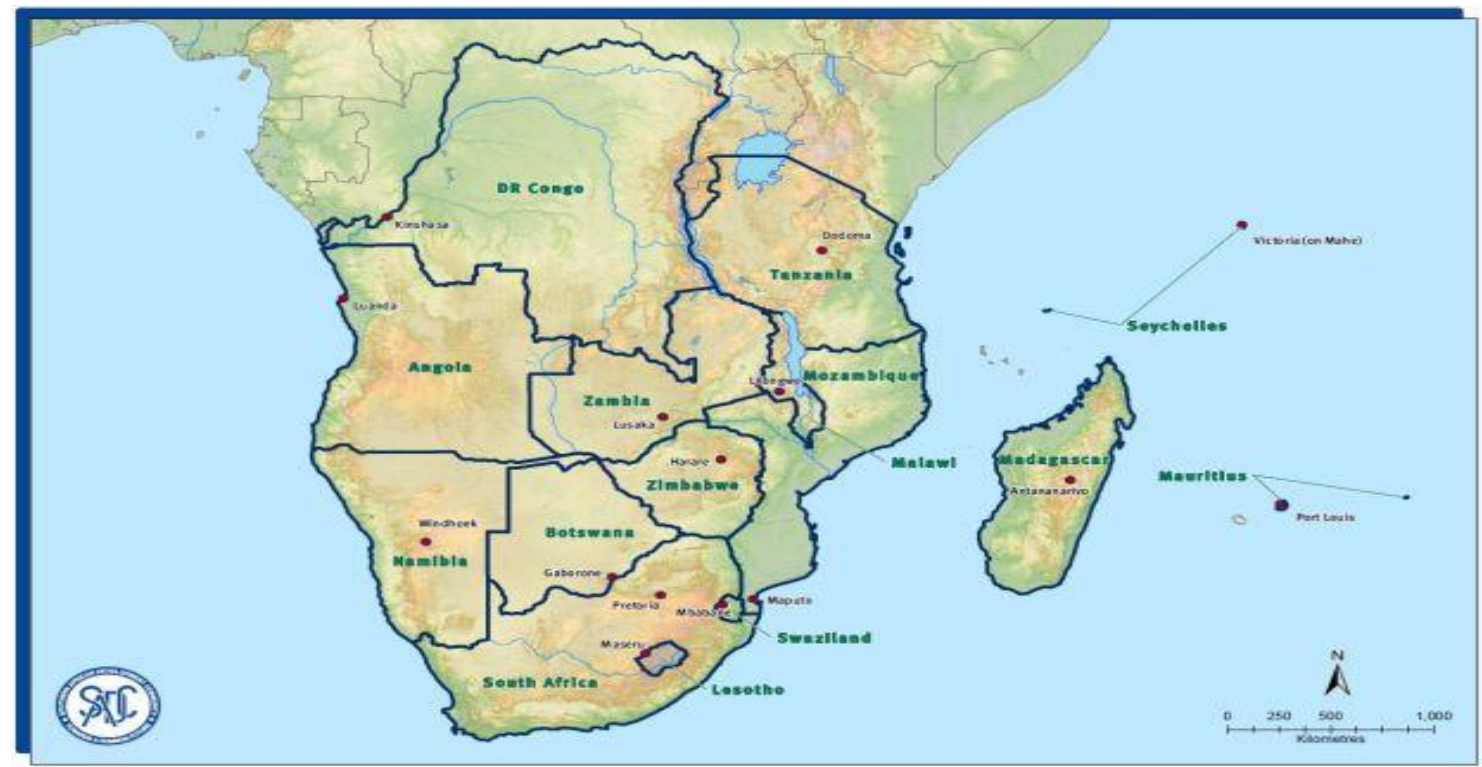

Fonte: Página da SADC. Disponível em: 〈http://www.sadc.int/about-sadc/overview/ >. 08/04/14.

É nesta região mais a sul da África Subsaariana ou do equador que encontramos o bloco econômico SADC em que Angola faz parte e, sobretudo tem muita influência. Desta forma, estamos diante da África Austral. Além disso, a SADC é o bloco mais emergente do continente africano no contexto atual segundo Rocha (2009). O bloco é formado de 15 membros no qual a Ilhas Seicheles está suspenso da organização desde 2011. A tabela 3 irá informar os membros que integram a região.

6 Estes informações foram fornecidas a partir da base de dados (parte sobre a população) do Ministério da Agricultura. Sitio: (www.countrystat.org). Angola. 


\section{Evolução recente da taxa de crescimento do PIB de Angola e posicionamento na região da SADC, efeitos na Região e em Angola}

4.1 Evolução da taxa do PIB real de Angola e posição na região

A SADC é uma região muito heterogênea e os países que a integram estão em estágios diferentes de desenvolvimento e com dinâmicas diferenciadas de crescimento, portanto, estes fatos têm colocado a Angola desafios sérios, atendendo à circunstância que durante 27 anos depois da independência o país ter estado numa situação de conflito militar interno permanente, com destruição de grande parte das infraestruturas econômicas e sociais (ROCHA, 2009, p.1).

Porém, Angola é um dos países da região da SADC que nos últimos anos tem mostrado indicadores muito acelerados de crescimento econômico, afirmando-se na classificação de posicionamento dos países que mais cresceram.

Neste caso, as principais garantias de estabilidade do crescimento econômico e da forte posição de Angola na região estão centradas em quatro pontos fundamentais: a estabilidade política, o aumento contínuo da produção de petróleo, a reabilitação das infraestruturas e a diversificação da economia.

Muitos economistas e políticos em Angola têm feito muitas criticas a dependência da economia para o setor petrolífero e aconselhando a diversificação da economia em prol de outros setores, e não do setor petrolífero. Essas críticas realmente tem os seus fundamentos devido ao baixo nível de absorção do emprego, expectativas de não existência de petróleo no futuro, quebra nos preços no mercado internacional, "peak oil entre 2010 a 2014 segundo o Banco Mundial”, etc. (ROCHA, 2011, p. 65), ou seja, realmente é necessário diversificar a economia para manter taxas elevadas de crescimento econômico evitando efeitos exógenos adversos ou de contexto internacional através da dependência do petróleo - quebras de preço, de produção, “de redução de $40 \%$ no uso do petróleo até 2014 através da poluição" (ROCHA, 2011, p. 63), entre outros.

Mas, muitas das vezes essas criticas tem sido bastante severas ao ponto de muitos esquecerem que foi graças a este setor que Angola conseguiu atingir como ainda atinge níveis elevados de crescimento econômico, alem de acomodar o abrandamento da economia através da crise e, com isso manter o seu posicionamento entre os países da África Austral que mais cresceram ou crescem. 
Não defendo a dependência da produção de petróleo, mas sim, a necessidade de se criar meios de não deixarmos à parte o contínuo aumento da produção através dos investimentos no setor com o intuito de alimentar de maneira eficaz os investimentos em setores que possam ajudar na política de diversificação da economia de forma sustentável. Portanto, nesta altura o contínuo investimento no setor é louvável e impulsionador para a "diversificação da economia que muito se defende" (AMBRÓSIO, 2014 apud AMBRÓSIO, 2008, p.149). Em alguns casos essa defesa ocorre forma muito abstrata sem que se pense na conjugação dos mesmos, isto é, aumento da produção petrolífera versus influenciador da diversificação da economia sustentável com vistas a elevar os níveis da taxa real de crescimento da economia angolana. Não obstante, este crescimento econômico, vai atrair e, -como tem acontecido- o investimento privado estrangeiro para a agricultura, gerando emprego e bem-estar para a população (ANIPAGENCIA NACIONAL DE INVESTIMENTO PRIVADO, 2012).

[...] Angola veio obtendo já a bastante tempo posições políticas muito fortes na África e em particular na SADC, porém, é necessário haver essa conjugação de estratégias (produção versos diversificação econômica) com vista ao peso crescente da economia na região e quiça na África, por formas a elevar ainda mais o posicionamento na região.

Mais abaixo, vamos mostrar a evolução crescente da produção do sector mineiro e do PIB petrolífero como indicador chave do crescimento da economia de Angola antes da crise financeira de 2008. Além disso, o gráfico abaixo mostra o quanto o sector mineiro influenciou na taxa de crescimento do PIB real do país, visto que após o conflito armado e atendendo a procura do petróleo, o governo angolano procurou investimentos externos para aumentar a produção de petróleo (MINISTERIO DOS PETROLEOS, MINPLAN, ANIP, 2004, 2005, 2006) para ofertar mais a nível internacional com objetivo de sustentar a produção em termos do PIB. Estes e outros fatores influenciaram de certa forma na posição da taxa real do PIB de Angola na região até 2007, embora se verificou uma quebra na época da crise mundial através de fatores já conhecidos como a quebra na produção e preços baixos do produto. 
Tabela 1- Produção de Petróleo Bruto e Diamantes

\begin{tabular}{c|c|c|c|c} 
Indicadores & $\mathbf{2 0 0 4}$ & $\mathbf{2 0 0 5}$ & $\mathbf{2 0 0 6}$ & $\mathbf{2 0 0 7}$ \\
\hline Petróleo Bruto (Mil Bbl/dia) & 989,02 & $1.246,28$ & $1.409,90$ & $1.697,33$ \\
\hline Diamantes (Mil quilates) & $6.265,8$ & $6.770,80$ & $9.269,90$ & $9.701,70$ \\
\hline
\end{tabular}

Fonte: Elaboração própria a partir dos dados do MINPLAN, 2011.

Gráfico 1 - Evolução do Petróleo ao Longo do Tempo (Mil Bbl/dia)

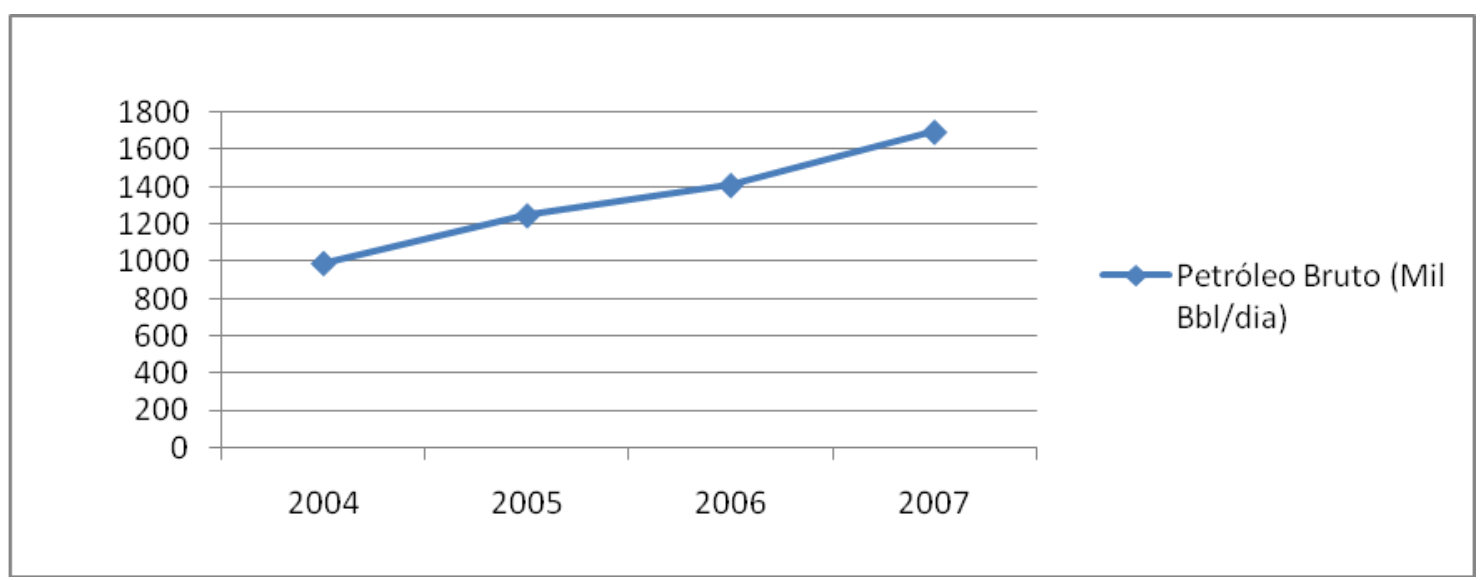

Fonte: Projeção do autor a partir dos dados do MINPLAN, 2011.

O gráfico abaixo mostra a diferença em termos de projeção dos indicadores bases da economia de Angola de forma mais geral, isto é, indicadores petrolíferos e não petrolíferos para justificar o quanto este setor ainda é importante principalmente para o fomento do setor adverso (não petrolífero).

Tabela 2 - Principais Indicadores Econômicos (em milhões de US\$)

\begin{tabular}{l|c|c|c|c}
\multicolumn{1}{c|}{ Indicadores } & $\mathbf{2 0 0 4}$ & $\mathbf{2 0 0 5}$ & $\mathbf{2 0 0 6}$ & $\mathbf{2 0 0 7}$ \\
\hline PIB petrolífero & $9.855,6$ & $17.038,9$ & $23.382,7$ & $33.173,3$ \\
\hline PIB não petrolífero & $9.150,5$ & $13.232,6$ & $18.598,2$ & $26.274,9$ \\
\hline P
\end{tabular}

Fonte: Elaboração própria a partir dos dados do MINPLAN, 2011.

Gráfico 2 - Evolução dos Principais Indicadores Econômicos (em milhões de US\$)

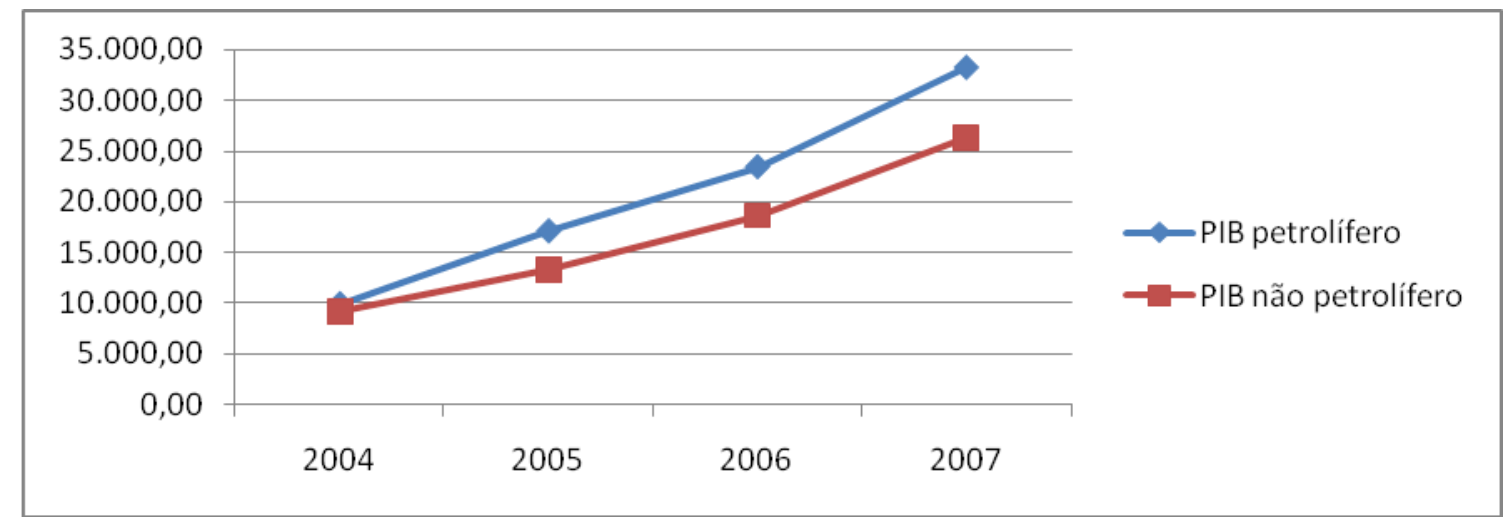

Fonte: Projeção do autor a partir dos dados do MINPLAN, 2011. 
Atento a Perspectiva Econômica em África, dizer que este estudo africano recente e muitos outros informados através do CEIC (Centro de Investigação Cientifica da Universidade Católica de Angola), do Ministério das finanças de Angola, mostram que o desempenho do PIB petrolífero ainda tem grande influência sobre o PIB total do país, ou seja, $48 \%$ do produto interno bruto de Angola ainda é arcada pelo sector mineiro, embora o sector diamantífero ofereça $1 \%$ e os demais sectores o restante (PERSPETIVA ECONÔMICA EM ÁFRICA, 2012, 2013). Portanto, conforme afirmei é necessário para além da diversificação da economia, manter os níveis de investimentos nesse setor por formas a garantir sempre o apoio ao crescimento da economia e a sua posição.

Chamo atenção ao seguinte, se tivermos que analisar os vários indicadores fornecidos por algumas instituições de renome como é o caso do Banco Mundial, percebe-se que em termos de produto interno Bruto a preços correntes, Angola perde para poucos países da região, como exemplo base, a África do Sul. Mas se analisarmos do ponto de vista do PIB em termos de taxa real de crescimento, embora com algumas variações cíclicas ao longo destes cinco anos, isto é, analisando a um horizonte temporal de 2002 á 2007, vamos notar que Angola soma pontos com relação as suas principais concorrentes, como o Malaui, Moçambique e Tanzânia.

Apesar de Angola cair algumas posições nos dois anos seguintes através do abrandamento da economia a nível mundial, ainda assim, continua a mostrar nos dias de hoje taxas de crescimento econômico sólidas em comparação aos outros países da região e do mundo. Entretanto, o país ainda se encontra na classificação daqueles países com indicadores de crescimento positivos no continente e no mundo.

Desta forma, os indicadores da tabela 3 abaixo, vai-nos ilustrar esse posicionamento da taxa real de crescimento do PIB antes e depois da crise de 2008, seus estados cíclicos para que fique mais clara a nossa discussão anterior.

Tabela 3 - Taxa de Crescimento do PIB Real dos países da SADC, antes e após a Crise Financeira Internacional á partir de 2006 a 2010 


\begin{tabular}{|c|c|c|c|c|c|c|c|c|}
\hline \multicolumn{4}{|c|}{ Antes da crise } & \multirow{2}{*}{$\begin{array}{c}\text { A } \\
\text { Média } \\
\text { 06-08 }\end{array}$} & \multicolumn{2}{|c|}{ Após a crise } & \multirow{2}{*}{$\frac{\text { B }}{\text { Média }}$} & \multirow{2}{*}{$\begin{array}{l}\text { Diferencial de } \\
\text { cresci. } \dot{\mathbf{x}}(\mathrm{B}-\mathrm{A})\end{array}$} \\
\hline Países da SADC & 2006 & 07 & 08 & & 2009 & 10 & & \\
\hline Angola & 19,5 & 23,9 & 2,4 & 19,1 & 2,4 & 3,4 & 5,8 & $-13,3$ \\
\hline Malaui & 7,7 & 5,8 & 8,6 & 7,4 & 7,6 & 6,6 & 7,1 & $-0,3$ \\
\hline Moçambique & 8,7 & 7,3 & 6,8 & 7,6 & 6,3 & 7,0 & 6,7 & $-1,0$ \\
\hline Tanzânia & 7,0 & 6,9 & 7,3 & 7,1 & 6,7 & 6,5 & 6,6 & $-0,5$ \\
\hline Madagáscar & 5,0 & 6,2 & 7,1 & 6,1 & $-3,7$ & $-2,0$ & $-2,9$ & $-9,0$ \\
\hline Lesoto & 4,7 & 4,5 & 4,7 & 4,6 & 3,0 & 2,4 & 2,7 & $-1,9$ \\
\hline I. Mauricias & 4,5 & 5,9 & 5,5 & 5,3 & 3,0 & 4,0 & 3,5 & $-1,8$ \\
\hline Botsuana & 5,1 & 4,8 & 3,1 & 4,3 & $-3,7$ & 8,6 & 2,5 & $-1,9$ \\
\hline Namíbia & 7,1 & 5,4 & 4,3 & 5,6 & $-0,8$ & 4,4 & 1,8 & $-3,8$ \\
\hline R.D. Congo & 5,6 & 6,3 & 6,2 & 6,0 & 2,8 & 7,2 & 5,0 & $-1,0$ \\
\hline I. Seychelles & 6,4 & 9,6 & $-1,3$ & 4,9 & 0,7 & 6,2 & 3,5 & $-1,5$ \\
\hline Suazilândia & 2,9 & 2,8 & 3,1 & 2,9 & 1,2 & 2,0 & 1,6 & $-1,3$ \\
\hline África do Sul & 5,6 & 5,6 & 3,6 & 4,9 & $-1,7$ & 2,8 & 0,6 & $-4,4$ \\
\hline Zâmbia & 6,2 & 6,2 & 5,7 & 6,0 & 6,4 & 7,6 & 7,0 & 1,0 \\
\hline Zimbábue & $-3,5$ & $-3,7$ & $-17,7$ & $-8,3$ & 6,0 & 9,0 & 7,5 & 15,8 \\
\hline
\end{tabular}

Fonte: Elaboração própria a partir dos dados de Matos all, 2011 apud FMI (World Economic Outlook Database), Abril-2011.

A tabela 3 demarca a idéia que viemos argumentando. Para ficar mais claro a análise, visto que queremos mostrar também a influência da crise financeira aos indicadores tabelados, buscaram-se os dados e anos que remarcam com maior evidência o crescimento econômico antes e o abrandamento após crise econômica de 2008.

Atento na tabela 3 nota-se que ainda que Angola tivesse um contínuo aumento do seu posicionamento em nível da região, ganhando principalmente das suas concorrentes mais próximas e demais economias da região, ela sofreu um deslize no seu crescimento. Ou seja, ganha posição entre os anos de 2006 a 2008 com uma média de 19.1. Mas, após a crise financeira, ou seja, no final da crise estes números decresceram entre 2,4 á 3,4, isto entre 2009 á 2010 com média de 5,8 perdendo posição principalmente para os principais concorrentes como o Malaui, Moçambique e Tanzânia.

Nesta altura o mercado petrolífero estava em crise, ou seja, "os preços a vista do petróleo caiu de US\$ 97, em média, em 2008 para US\$ 44 no primeiro trimestre de 2009, visto que a Organização dos Países Produtores de Petróleo (OPEP) reagiu com um corte nas quotas de produção de petróleo e, como conseqüência, a quota de Angola foi reduzida 
em cerca de 20\%" (BICUDO, 2012, p. 109 apud INTERNATIONAL MONETRY FUND, 2009) o que influenciou negativamente o desempenho do PIB.

É preciso não esquecer que para além da influência negativa da crise financeira e do baixo preço do petróleo a nível mundial, a outra variável que também veio influenciar o enfraquecimento das economias no mundo foi à crise dos alimentos.

Observando novamente o quadro, entre todos os países, o que mais chamou atenção em decorrência de toda essa situação pós-crise foi o Zimbábue, visto que antes da crise teve enormes dificuldades de crescimento, sendo este indicado em último na tabela, mostrando assim valores negativos de $-3.5 ;-3,7$ e $-17,7$, e assim foi classificado como a economia que menos crescia. Mas, noutrora parece que a crise teve grande influência no seu crescimento e posicionamento. Observe que a Zâmbia é um caso praticamente análogo.

Ora, nota-se que após crise, o crescimento econômico do Zimbábue começou assumir valores positivos obtendo desta forma taxas de crescimento de 6,0 e 9,0, com variação média de 7,5 e assim considerado como a melhor posição dos anos de 2009 e 2010. Ademais, por incrível que pareça é a economia que menos cresceu antes da crise e que mais cresceu pós-crise, principalmente em 2010, porém, seria interessante estudar de forma particular este fenômeno visto que, quando uns decresciam por conta da crise mundial, este país crescia.

Por fim, atento ao mitigar do crescimento econômico de Angola, o governo tem criado um conjunto de políticas estruturais e entre outras com o objetivo de evitar constrangimentos futuros e assim se mantendo na corrida dentre os países que mais crescem. Alem do mais, esse crescimento econômico tem vindo a influenciar as políticas do governo de âmbito social através do OGE (Orçamento Geral do Estado) como, por exemplo, aumento de habitação, de escolas, de hospitais, de saneamento básico, diminuição da pobreza e outros (MINPLAN: PLANO NACIONAL DE DESENVOLVIMENTO, 2013 - 2017).

\subsection{Efeitos econômicos na Região da SADC}


O objetivo é saber se estas taxas de crescimento do PIB real de Angola tem tido efeitos positivos na região, não obstante o seu posicionamento, visto que estamos perante a um bloco econômico muito emergente e com dificuldades de obter fortes presenças de troca com outros blocos internacionais. Conforme Rocha (2009), a SADC é uma região com grande heterogeneidade e o desenvolvimento destes países estão em estágios diferentes e com dinâmicas diferenciadas de crescimento. Aí que, mesmo com a crise financeira de 2008 via-se que alguns países da região ainda tendiam a um crescimento diferenciado aos demais.

De acordo com Rocha (2009), “a proximidade de igualdade de crescimento econômico, de relação econômica entre os países da região ainda não é satisfatória, visto que a maioria dos países ainda tem problemas de infraestruturas econômicas", Angola não foge a regra. Esse fator tem influenciado os países da região no fortalecimento de posições econômicas e efeitos positivos na região desde que não haja muitas disparidades ou diferenças econômicas.

Ainda no campo das relações comerciais ou econômicas através dos efeitos das taxas crescentes de muitas das economias da região, vê-se vantagens em termos competitivos de poucos países ou de apenas um, a África do Sul, visto que é um dos poucos países da região com poucos problemas de infraestruturas e com uma estrutura econômica bem consolidada na região, porém, isso faz com que ganhe mais vantagens tornando assim a região menos homogênea e menos próxima em termos econômicos. Apesar de alguns saírem em vantagem, não é satisfatório para o bloco visto que o bloco sofrerá muitos choques externos em competição com outros blocos fortes na arena internacional, é o caso da União Européia (U.E).

Aliás, Matos (2011) chama atenção aos países da região com relação a choques externos. Ora, se os países do bloco não se unirem nas várias facetas socioeconômicas, sempre terão dificuldades de competir com outros blocos do mundo, por sua vez, esses choques adversos tenderão a continuar. Por consolidação desta parte, finalmente na próxima subseção propõem de forma resumida algumas estratégias internas em Angola com vistas a uma unificação das trocas entre os países da região sem pensar em certa 
parte nas vantagens em termos de posição de crescimento, mas com isso influenciar a economia da região.

\subsubsection{Influência e Proposta Atual}

Apesar de Angola ter um posicionamento forte de taxa de crescimento na região, não se vê ainda muita influência da sua economia na SADC, embora se reconheça que,

A SADC é constituída por países muito diferentes entre si em inúmeros atributos que a abertura dos mercados e a livre concorrência não são suficientes para provocar uma convergência real entre as diversas economias na base da qual as taxas tendências de crescimento do PIB podem aumentar o volume de comércio incrementar-se (ROCHA, 2009, p.143).

Observando a realidade atual, todavia, nota-se que o governo de Angola está a evidenciar esforços para superar está situação. Vê-se que em nível de infraestruturas ferroviárias e rodoviárias (PEA, 2013, CMI, 2011), Angola tem um projeto interno em curso de longo prazo que poderá em um futuro breve influenciar a atividade econômica na região através de corredores (vias) que chegarão para alguns países da região, para que numa relação de proximidade todos tenha vantagem e assim se evite choques externos. Além disso, outros países da região também têm o transporte como força motriz do impulsionamento da relação econômica entre os países da SADC.

Apesar de Angola manter essa posição privilegiada entre os países que mais

crescem, é necessário que este crescimento venha influenciando nos próximos anos a economia da região sem que haja disparidades ou diferenças em termos de integração ou cooperação econômica. Contudo, é proposto o seguinte:

- Que a sua base econômica interna seja diversificada, aproveitando desta forma o desempenho da produção de petróleo e seus derivados;

- Continuidade do fortalecimento e aprimoramento das infraestruturas econômicas internas para influenciar a integração econômica como também social na região.

E para os países do bloco de forma geral é necessário:

- Estimular o comércio de produtos e serviços entre os países membros; 
- Diminuir a pobreza da população de todos os países membros e melhorar a qualidade de vida;

- Maximizar o uso dos recursos naturais da região;

- Promover o crescimento sustentável dos países do bloco;

- Promover a paz e bons relacionamentos políticos na região, atuando para evitar conflitos e guerras;

- Cooperação socioeconômica e política na região;

- Buscar soluções em comum para os principais desafios da região;

- Redução e unificação das tarifas alfandegárias e taxas de importação e exportação nas relações comerciais entre os países membros (AMBRÓSIO, 2014, p. 87 apud SADC, 2012).

\subsection{Efeitos Econômicos em Angola}

Angola após conflito armado vem se mostrando nesses últimos anos como um dos poucos países em que economia tem crescido a bom ritmo em nível de África e do mundo. Com efeito, atento a este crescimento, internamente o governo angolano tem evidenciando esforços com o propósito de controlar de forma mais afincada a sua política macroeconômica como destaque a monetária, cambial e fiscal para que tome o controle ideário de como a estrutura econômica está sendo guiada dentro (diversificação da economia, etc.) e fora do território nacional (reservas internacionais, etc.).

Também está a criar infraestruturas de apoio à economia como o corredor de estradas nacionais (MINTRANS, 2008), telecomunicações, águas, energia, urbanização e ambiente, obras públicas e correios. Contudo a nível internacional, conseguiu diminuir bastante a dívida pública, aumentou as reservas internacionais líquidas etc. Este fator influenciou também o grau de investidores estrangeiros a investir no país (ANIP, 2012).

Porém, observe abaixo a evolução da taxa de crescimento do PIB e projeções no período 2004 á 2013 e indicadores econômicos do período de 2010 á 2013, para que proporcione uma visão mais realista da evolução da economia angolana face os argumentos do trabalho.

Tabela 4 - Evolução da Taxa de Crescimento do PIB Real

\begin{tabular}{l|c|c|c|c|c|c|c|c} 
Indicador & $\mathbf{2 0 0 6}$ & $\mathbf{2 0 0 7}$ & $\mathbf{2 0 0 8}$ & $\mathbf{2 0 0 9}$ & $\mathbf{2 0 1 0}$ & $\mathbf{2 0 1 1}$ & $\mathbf{2 0 1 2}$ & $\mathbf{2 0 1 3}$ \\
\hline PIB Real & 19,5 & 23,9 & 2,4 & 2,4 & 3,4 & 3,9 & 6,8 & $7,2(\mathrm{p})$ \\
\hline
\end{tabular}

Fonte: Elaboração própria a partir dos dados do Banco Mundial (2013, 2014). 
Gráfico 3 - Evolução da Taxa de Crescimento do PIB Real

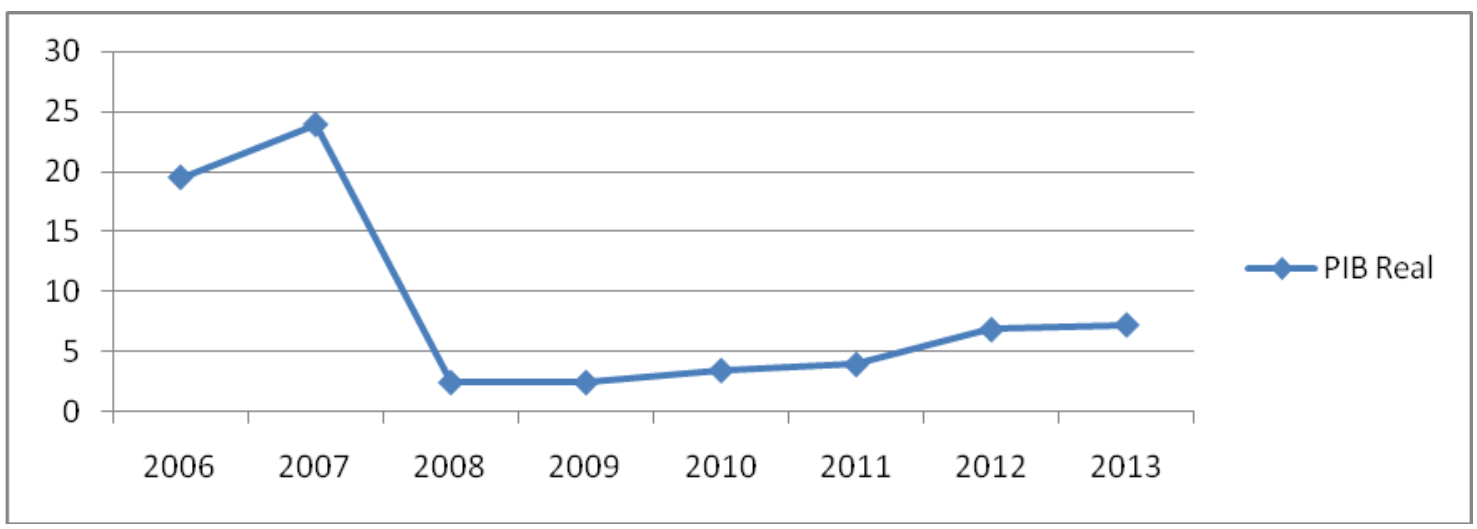

Fonte: Projeção do autor a partir dos dados do Banco Mundial (2013, 2014).

Tabela 5 - Indicadores Econômicos (em porcentagens)

\begin{tabular}{l|c|c|c|c} 
Indicadores mais recentes & 2010 & 2011 & 2012 & 2013 \\
\hline Crescimento real do PIB & 3,4 & 3,9 & 6,8 & $7,2(\mathrm{p})$ \\
\hline Crescimento real do PIB per capita & 0,6 & 0,8 & 5,5 & 4,4 \\
\hline Inflação medida pelo IPC & 14,5 & 13,5 & 10 & 9,4 \\
\hline Saldo orçamental \% PIB & 6,8 & 7,3 & 4,7 & Cinco \\
\hline Balança corrente \% PIB & 8,9 & 13,5 & 10,1 & 9,8 \\
\hline
\end{tabular}

Fonte: Elaboração própria a partir dos dados do BNA, MINFIN, MINPLAN, B.M, 2010, 2011, 2014.

\section{Considerações finais}

O petróleo em Angola foi descoberto em 1950. A sua exploração começou a ganhar peso a partir de 1970, fase em que houve a abertura de poços de petróleo modificando desta forma o panorama da indústria extrativa na época. Mas, seu volume de exportação veio destronando o "café" nos anos de 1973, sendo este o principal produto de ganhos de Angola nesta fase (DILOLWA, 1978, p. 286 a 287). Assim, desde a saída do poder colonial, guerra civil e até o contexto atual, o crescimento da economia de Angola sempre esteve muito dependente da exploração petrolífera. O peso da sua contribuição após a guerra civil para o PIB, já ultrapassava em mais de 50\%. Entretanto, nesta fase, praticamente os outros setores estavam inoperantes devido a fatores políticos (guerra), ou seja, não tínhamos uma economia diversificada para fazer face a essa dependência. 
Contudo, após 2002 a sua oferta através dos elevados níveis do preço do petróleo foi fenomênico para o país, influenciando assim altas taxas de crescimento do PIB real de Angola, obtendo com isso forte posição na SADC antes da crise econômica de 2008, como mostra a tabela 3 acima.

Mas, nota-se que este fator taxas elevadas de crescimento e uma das economias mais rica da região (relativo também a posição econômica), ainda não tem influenciado de forma positiva a economia da região, não obstante o seu peso econômico. Porém, é necessária que Angola procure o mais rápido possível contornar essa situação já que o objetivo da região é manter uma região melhor conjugada onde todos saem a ganhar principalmente no que refere a trocas comerciais.

No contexto angolano, apesar de algumas criticas relevantes que se vem sendo feitas desde o passado sobre o aproveitar do crescimento econômico para o desenvolvimento econômico e social de uma franja da sociedade angolana. Conforme Hodges (2002), "Depois de o governo abandonar o socialismo de Estado no início da década de 90, abraçaram um capitalismo distorcido pela manutenção de mecanismos dirigistas e não transparentes de atribuição de recursos. A elite ascendente constituiu fortuna com base nas concessões diamantíferas, na privatização de propriedades do Estado e no acesso privilegiado a empréstimos bancários e divisas. O Estado não prestou contas de uma parte importante das enormes receitas públicas geradas pela venda do petróleo angolano. Os interesses enraizados num sistema de clientelismo estatal travaram as reformas que permitiriam fortalecer a responsabilização do Estado e a transparência na gestão dos recursos públicos. Por outro lado, a má gestão e a guerra devastadora minaram os sectores não petrolíferos da economia e lançaram a maior parte do povo angolano na pobreza".

Essas críticas têm mudando o panorama da política angolana no quesito desenvolvimento econômico e social do país. Um exemplo claro, se pode verificar no campo social com realce a diminuição do índice de pobreza, com menos de 50\%, conforme o Diretor Geral da FAO numa entrevista dada a Voz da América, que dizia: "Angola atingiu as metas de combate à fome e à pobreza". Também, podemos observar 
que a esperança de vida aumentou para mais de 50 anos, fato que não se observava anos atrás.

Por conseguinte, a luta pelo desenvolvimento econômico e social de uma sociedade para muitos autores não se faz só com o estado de providencia, aliás, A. Smith no seu livro sobre a riqueza das nações já chamou atenção apesar de algum extremismo segundo defensores heterodoxos. Contudo, é necessário o envolvimento privado para equilibrar o peso ou responsabilidade estatal no que se refere à razão da dignidade a realidade ou unidade social através da diversificação da economia.

Angola não foge a regra, apesar de se verificar ainda alguns fatores constrangedores e inaceitáveis que devem ser eliminados, como a forte interferência do poder político na esfera privada ou na implantação de uma empresa ou indústria nascente, elevada burocracia nos processos de criação de uma empresa privada, influencia em vantagem de outrem (concorrência desleal), corrupção e outros.

Assim, afirma Messiant no Relatório de Progresso de 2004 a 2009 que, "o novo capitalismo angolano não é liberal, caracterizando-se antes pelo contrário, pela extrema interferência do poder político na afetação das posições de acumulação e na possibilidade real, para os vários cidadãos, de desenvolver as suas riquezas. ${ }^{7}$ Portanto, concordo com a autora visto que é necessário se rebuscar o verdadeiro modelo clássico de livre iniciativa privada sem a forte interferência do poder público, por formas a que a sociedade crie a sua própria riqueza sem grande dependência do poder. Existe o privado, mas a concorrencial desleal por interferência política é bem notável em muitos casos.

Essa abertura ao empresariado privado poderá ajudar a sanar muitas dificuldades que o governo angolano tem vindo a mostrar no que se refere ao desenvolvimento

7 Christine Messiant: (Poder hegemônico em multipartidarismo, pag. 6) através do PROJECTO de PESQUISA - ACÇÃO (processos de democratização e desenvolvimento em Angola e na África Austral): $\begin{array}{llll}\text { Relatório de } & \text { Progresso } & \text { 2004/2009. } & \text { Disponível }\end{array}$ em: <http://www.ces.uc.pt/conferenciaangola2009/pdf/RelatorioPortNetCoresBom.pdf $>$. Acesso em Abril de 2014. 
econômico e social do país. Além do mais, a política de redistribuição e alocação deve ser um dado indispensável.

Por fim, Angola ainda tem fortes tendências de estar entre os países que mais vem crescendo em nível da África, da África Austral e do mundo, entretanto, também deve aproveitar esse momento de glórias para contribuir na economia da região e do país com políticas fortemente voltadas a educação, saúde, habitação condigna, eliminação da extrema pobreza entre outras, além de manter o seu peso na economia da região entre os países que mais crescem.

Por conseguinte, os resultados indicam de alguma forma, a influência da taxa do PIB real de Angola sobre a evolução econômica do país. Ademais, apesar do peso e/ou da posição da taxa do PIB real de Angola na SADC, este ainda não tem grande influência sobre o progresso econômico na região.

\section{Referencia bibliográficas}

AÇÃO PARA O DESENVOLVIMENTO RURAL E AMBIENTE (ADRA): Plano Estratégico 2012-2016. Angola, Julho, 2011. Disponível em: <http://www.adraangola.org/wp-content/uploads/2012/11/ADRA-PE-2012-2016-Documento

Principal1.pdf $>$. Ultimo acesso em Abril de 2014.

AMBRÓSIO, Heitor. Desenvolvimento Econômico, Integração Comercial e Desigualdades Regionais na África Austral e dentro de Angola. 2014. Dissertação (Mestrado em Economia) - Pós-Graduação em Economia, UFU, Uberlândia - MG.

ANIP (AGENCIA NACIONAL DE INVESTIMENTO PRIVADO): Investimentos em Angola, ANIP, 2012. Disponível em: 〈http://www.anip.co.ao $>$.

BANCO MUNDIAL: Indicadores. Disponível em: <http://data.worldbank.org/indicator/NY.GDP.MKTP.KD.ZG. Acesso em Abril de 2014.

BICUDO, Raphael. A Economia Social de Angola e da África Subsaariana. São Paulo: Xamã Editora, Brasil, 2012. 
BRESSER-PEREIRA, Luiz Carlos. Crescimento e Desenvolvimento econômico. São Paulo, Brasil, 2008. Disponível em: <http://www.bresserpereira.org.br/Papers/2007/07.22.CrescimentoDesenvolvimento.Ju nho19.2008.pdf> acesso em fev. de 2014.

DILOLWA, C. Rocha. Contribuição à História Económica de Angola. Luanda: Editoral Nzila, Angola, 1978.

FAO (ORG. DAS NAÇÕES UNIDAS PARA ALIMENTAÇÃO E AGRICULTURA): Angola atingiu as metas de combate à fome e à pobreza. 2014. Disponível em: 〈http://www.voaportugues.com/audio/audio/298043.html>. - Angola atingiu as metas de combate à fome e à pobreza. 2014. Disponível em: <http://www.voaportugues.com/content/fao-angolaalimentacao/1687319.html $>$.

FUNDO MONETARIO INTERNACIONAL (FMI): Transcrição de uma chamada de Conferência em Angola. Acordo stand-by com Angola em 2009. Novembro, 2009. Disponível em: 〈http://www.imf.org/external/np/tr/2009/tr112509.htm>. Acesso em Abril de 2014.

HODGES, Tony. Angola - Do Afro-Estalinismo ao Capitalismo Selvagem. Lisboa: $2^{\mathrm{a}}$ ed. Principia editora, Portugal, 2002.

BICUDO, Raphael. A Economia Social de Angola e da África Subsaariana. São Paulo: Xamã Editora, Brasil, 2012.

INSTITUTO CHR MICHELSEN (CMI/CEIC): Reformas ao Processo orçamental e Gestão das Finanças Públicas de Angola. A crise foi um sinal de alarme. 2010, p. 46. Relatório. Disponível em: 〈http://www.cmi.no/publications/file/4260-reformasprocesso-orcamental-gestao-financas.pdf $>$. Acesso em Abril de 2014. Relatório sobre as infraestruturas angolanas numa perspectiva regional. CMI/CEIC, Angola, 2011.

MAPA (SADC). Disponível em: 〈http://www.sadc.int/about-sadc/overview/ 〉.

MATOS O., MONTEIRO S. e SOMA D. Choques Externos e Respostas de Políticas nos Países da Comunidade de Desenvolvimento da África Austral (SADC). Banco Nacional de Angola, Luanda, 2011. Artigo. Disponível em: 〈http://www.bna.ao〉. Acesso em fev. de 2013.

MINPLAN (MINISTÉRIO DO PLANEAMENTO DE ANGOLA): Plano Nacional 20102011. Angola, Outubro 2009. Disponível em: 〈http://www.minplan.gov.ao〉. Acesso em jul. de 2013. . Plano Nacional de Desenvolvimento 2013 - 2017. Angola, Dezembro, 2012. Disponível em: 〈http://www.minfin.gv.ao/fsys/PND.pdf >. Acesso em Dez. de 2013. 
PEA (PERSPECTIVA ECONÔMICA EM ÁFRICA): Economia em Angola. PEA, 2013. Disponível em: <http://www.africaneconomicoutlook.org>. Acesso em jun. de 2013.

ROCHA, Manuel J. Alves. "Os Problemas da Integração Econômica na SADC e a Posição de Angola". Revista do Centro de Educação e Letras da Unioeste. v. 12, $\mathrm{n}^{\circ} 1$, p.139 a 158. $\mathrm{I}^{\circ}$ Semestre - Campus de Foz do Iguaço, 2009. Disponível em: <erevista.unioeste.br/index.php/ideacao/article/download/5032/3787 >. Acesso em dez. de 2012. . Alguns temas estruturantes da Economia Angolana: As crônicas no jornal Expansão 2009-2011. Luanda: Edições de Angola, 2011. Industrialização e diversificação da economia. Jornal Expansão (Opinião). Angola, Luanda, 2012. Disponível em: <http://expansao.sapo.ao/home/opinioes/colunistas/Artigos/manuel_alves_da_rocha>. Acesso em jul. de 2012. Infraestrutura em África. PEA, 2013. Disponível em: <http://www.africaneconomicoutlook.org/po/outlook/trade_policies/desenvolvimentos -da-integracao-regional-em-africa/>. Acesso em jun. de 2013.

ROSADO, Carlos. Acordo Stand-by é a melhor coisa que aconteceu ao país. Jornal Angola Press. Angola, Luanda, 2013. Artigo. Disponível em: <http://www.angonoticias.com/Artigos/item/37294/acordo-stand-by-e-a-melhor-coisaque-aconteceu-ao-pais $>$.

SANTOS, M. A NATUREZA DO ESPAÇO: Técnica e tempo. Razão e Emoção. São Paulo: $2^{\circ}$ ed. Hucitec, Brasil, 1997.

SANTOS, M. A Ubarnização Brasileira. São Paulo: Hucitec, Brasil, 1993.

SILVA, V. A. C. Regionalismo: o enfoque metodológico e a concepção histórica. In: SILVA, M. (org.) República em migalhas: história local e regional. São Paulo: Marco Zero, Brasil, 1990.

Outros sítios interessantes:

ANIP (AGENCIA NACIONAL INVESTIMENTO PRIVADO DE ANGOLA): Disponível em: <http://www.anip.co.ao/>.

BNA (BANCO NACIONAL DE ANGOLA): Indicadores Econômicos. Disponível em: <www.bna.gov.ao $>$.

Banco de Desenvolvimento Africano: Indicadores Econômicos. 2011. Disponível em: <www.afdb.org >. Acesso em Nov. de 2012.

GOVERNO DE ANGOLA. Disponível em: 〈www.governo.gov.ao $>$.

MINISTERIO DOS PETRÓLEOS. Disponível em: 〈www.minpet.gov.ao〉.

MINTRANS (MINISTERIO DOS TRANSPORTES): Infraestruturas rodoviárias $e$ ferroviárias. 2012. Disponível em: 〈www.mintrans.gov.ao > 
MINFIN (MINISTERIO DAS FINANÇAS): Indicadores Econômicos, 2010. Disponível em: 〈www.minfin.gov.ao .

MINPLAN (MINISTERIO DO PLANEAMENTO): Indicadores Estatísticos, 2011. Disponível em: <www.minplan.gov.ao>.

\title{
POSITION OF GDP GROWTH OF ANGOLA IN SADC BEFORE AND AFTER THE CRISIS OF 2008 AND EFFECTS ON THE ECONOMY OF THE REGION AND COUNTRY
}

\begin{abstract}
The objective of this paper is to show a comparative way the behavior of the growth rate in real GDP of Angola in relation to other SADC countries and their position in the region. Also, it is intended to know if this behavior has had positive effects on the development of the regional economy and the country. Since 2004, Angola has shown high levels of GDP growth rates influenced by political stability, increased production and export of oil. However, this fact has resulted in the entry door to foreign investors, in addition to increasing its position in SADC. Moreover, the government has increased investment in infrastructure to support economic development and diversify the economy to avoid future adverse shocks to production and export of oil and avoiding economic cycles, thereby ensuring strong position in the region. Moreover, this effect of GDP growth has created other structural and cyclical effects positively as increased employment, income, reduction of extreme poverty, inflation and the strengthening of state institutions through the democratic spirit among others (MINPLAN: NATIONAL DEVELOPMENT, 2013 - 2017).
\end{abstract}

KEYWORDS: GDP; Position in SADC; Economy; Society ;Angola. 